\title{
OCCUPATIONAL DERMATITIS
}

BY

\author{
A. THELWALL JONES
}

Liverpool

Dermatitis is any inflammation characterized by the classical signs of redness, swelling, heat and pain. It is a non-specific reaction of the skin to an irritant and cannot be considered an entity. Occupational dermatitis is such a reaction produced by, or aggravated by, an irritant encountered during the course of employment. At the present time the word dermatitis is almost synonymous with occupational skin disease and the word has unfortunately become of more legal than medical significance. In view of the diversity of industrial processes and the wide range of substances which will produce irritation of the skin in certain people with average skins, it is not surprising that, with few exceptions, the eruption is not characteristic. Pain is not usually a dominant feature and is more commonly replaced by itching. The onset is occasionally sudden, but more often insidious. The appearance of the skin eruption is proportional to the severity of the reaction produced by the causative agent and the stage at which the eruption is seen. These two factors are more important than the nature of the causative agent in considering the appearance $\mathrm{cf}$ the eruption, although some agents produce a constant and characteristic lesion. The usual sequence of events is erythema, oedema, papules, vesicles, or more rarely bullae which on rupture exude serum. The serum dries and produces crusts. When oedema of the prickle cells occurs the granular and horny layers are imperfectly formed and adhere together to produce scales. The appearance of the eruption is frequently complicated by subsequent scratching and infection.

Pathological changes in the skin accompany the signs. The blood vessels of the corium are dilated and there is exudation of lymph and infiltration of small round cells. The cells of the epidermis are swollen and separated by fluid which produces spaces forming visible vesicles. The disease produced is the reaction of the skin to an irritant which may reach the skin from without or within. The eruption arising from the action of an external irritant is the more frequent, but many substances are known to cause skin rashes when taken internally, and possibly eczema is a type of dermatitis produced by an irritant resulting from metabolic processes.
As has been shown by Graham-Little (1935), the occurrence of occupational dermatitis is of great social importance. The reports of the Chief Inspector of Factories show that 8926 cases of dermatitis were voluntarily notified in 1943, compared with 8802 in 1942, 4744 in 1940, 2952 in 1939 and 2195 in 1938 . These cases may be considered a fair sample of those which occur annually in industry, but no complete figures are available. The American Public Health Service made studies among more than 100,000 workers in various factories and found that in the period of a year about 1 per cent. of all workers in those factories were affected with occupational dermatitis, though burns, splashes of acid or alkalis or pyogenic infections of occupational skin wounds were not included (Schwartz, 1943a). The incidence of the disease varies widely in different industries, but many cases of industrial dermatitis occur among Engineers, Dyers, Metal Workers, Textile Workers, Chemical Workers, Painters and Polishers.

The following figures are representative of the incidence of skin disease in the chemical industry. The cases were observed during the six years 193541 , when every man received a complete physical examination.

Table 1 records the number of employees engaged in the industry, in age groups, and Table 2 shows the type of skin disease discovered.

TABle 1

\section{EMPLOYEES EXAMINED}

\begin{tabular}{|c|c|c|c|c|c|}
\hline $\begin{array}{l}\text { Number } \\
\text { examined }\end{array}$ & & & & & Age \\
\hline 18 & . & $\ldots$ & . & .. & 15 \\
\hline 247 & $\ldots$ & $\ldots$ & $\ldots$ & $\ldots$ & $15-20$ \\
\hline 331 & . & . & . & .. & $20-25$ \\
\hline 336 & $\ldots$ & $\ldots$ & $\ldots$ & $\ldots$ & $25-30$ \\
\hline 382 & $\ldots$ & $\ldots$ & $\ldots$ & $\ldots$ & $30-35$ \\
\hline 353 & $\ldots$ & $\ldots$ & $\ldots$ & $\ldots$ & $35-40$ \\
\hline 318 & $\ldots$ & $\ldots$ & $\ldots$ & $\ldots$ & $40-45$ \\
\hline 302 & $\ldots$ & $\ldots$ & .. & $\ldots$ & $45-50$ \\
\hline 276 & $\ldots$ & . & . & . & $50-55$ \\
\hline 200 & $\ldots$ & $\ldots$ & $\ldots$ & $\ldots$ & $55-60$ \\
\hline 203 & .. & .. & .. & .. & $60-65$ \\
\hline
\end{tabular}

Total 2966 
TABLE 2

\section{TYPE OF SKIN DISEASE}

\begin{tabular}{|c|c|c|c|c|c|}
\hline Acne, including oc & cup & na & & & 169 \\
\hline Occupational dern & latit & excl & 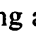 & $\ldots$ & 75 \\
\hline Eczema & $\ldots$ & $\ldots$ & $\ldots$ & $\cdots$ & 21 \\
\hline Varicose eczema & . & $\cdots$ & $\cdots$ & $\cdots$ & 10 \\
\hline Psoriasis . . & $\ldots$ & $\ldots$ & $\cdots$ & $\ldots$ & 9 \\
\hline Impetigo & .. & $\ldots$ & $\cdots$ & $\cdots$ & 6 \\
\hline Seborrhoea .. & . & $\ldots$ & . & $\cdots$ & 44 \\
\hline Acne Rosacea & $\ldots$ & $\ldots$ & . & $\cdots$ & 3 \\
\hline Fungus Infections & $\ldots$ & . & . & $\cdots$ & 4 \\
\hline Scabei & . & . & $\ldots$ & $\cdots$ & 1 \\
\hline Furunculosis & . & $\ldots$ & . & $\ldots$ & 10 \\
\hline Urticaria & .. & $\ldots$ & . & $\cdots$ & 5 \\
\hline Alopecia & $\ldots$ & $\ldots$ & $\ldots$ & $\therefore$ & 1 \\
\hline Ichthyosis .. & . & . & . & . & \\
\hline & & & tal & & \\
\hline
\end{tabular}

Practically every occupation can cause skin irritation and estimates of the relative prevalence of occupational compared with other skin affections vary between 2 and 20 per cent., 6 per cent. being a conservative estimate (White, 1928). Innumerable substances produce dermatitis but among the common ones are alkalis, acids, oil, degreasing agents and sugar, dough, salts of chromic acid, dyes, dinitrochlorbenzene, formaldehyde, tar and naphtha; soapy water, petroleum products, dyes and intermediates, paints, cleansing preparations, hair tonics and lime, chrysanthemum, pyrethrum, geranium and many types of bulb. Paraphenylenediamine is a common constituent of dyes for fur and hair, and is a powerful sensitizing agent. Many drugs applied locally will produce skin reactions, and the use of atropine is sometimes followed by dermatitis of the face. Cleansers such as alkalis, bleach, solvents and abrasives are often the cause of occupational dermatitis rather than the contacts which they are called upon to remove and a factor of importance in considering the prevention of the disease. A comprehensive list of causes has, however, been compiled by Schwartz (1943b); and O'Donovan (1932) stressed the importance of dermatitis arising in the home, and suggested the following classification of skin diseases caused by agents acting externally:

1. Mechanical or physical agents.

2. Plants and their products.

3. Living agents.

4. Chemicals.

(a) Inorganic acids and salts.

(b) Hydrocarbons, oils, tar, pitch, anthracene.

(c) Dye products.

Most cases of occupational dermatitis may, however, be arranged under headings describing the main action of the causative agent:

1. Mechanical. Inert dusts, e.g. sand, pumice, silica.

2. Macerative. Water and alkalis.

3. Fat solvent. Petrol, paraffin, benzene.

4. Chemically irritative. Acids and alkalis, dyes, mineral oils.

\section{Types of Occupational Dermatitis}

\section{A. Frimary Skin Irritants}

These produce clinical irritation of the skin in the majority of persons who have not been previously sensitized to the causative agent. They may give rise to non-characteristic and characteristic eruptions. The former comprise the majority of cases. The lesions may be confused with a number of infective and constitutional skin diseases, but in the troublesome type of case the differential diagnosis is between constitutional eczema and occupational dermatitis, between a skin eruption produced by internal and one by external irritation; while the latter are a group of less common but specific types of lesion, such as the rashes produced by oil and the acne produced by chlorinated hydrocarbons.

\section{B. Secondary Skin Irritants}

These produce reactions only in the skin of persons who are hypersensitive, the sensitization being acquired by contact with the causative agent. This type of dermatitis is less frequent than that produced by primary skin irritants, but is often more severe, and the disease may be protracted and subject to relapse on recontact.

Over a period of ten years, 92 cases of noncharacteristic occupational skin disease have occurred in a chemical industry, which employs, on the average, 2000 people. Of these 67 were caused by primary skin irritants, and 25 by secondary skin irritants. Tables 1 and 2 record the majority of the cases and also the incidence of all skin diseases during a six-year period. Cases of occupational dermatitis occurring subsequent to this review are included in the following classification. The progress of many of the cases recorded has been observed over a period of several years.

\section{A. Primary Skin Irritants}

1. Non-characteristic Eruptions. The signs of inflammation are evident in the area exposed to the causative agent. In its mildest form the disease is a localized erythema and if the case is immediately removed from contact with the irritant and simple remedies applied an early and permanent cure is to be anticipated. Early removal from contact is a measure of outstanding importance in order to prevent widespread disease which may result in skin sensitivity to many agents. In the mild type of disease the worker usually becomes immune, but with severe and extensive lesions no immunity is to be expected. In severe cases the lesions are eczematous in type, the features of which are described later.

It is possible to distinguish three groups of cases which arise from primary skin irritants.

(a) The group of cases described above which can usually be readily explained. Forty-one of the 67 cases due to primary skin irritants belonged to this group. 
(b) A group of cases arising in employees who have been engaged on the same work for many years without any evidence of skin disease. Eighteen of the 67 cases belonged to this group. They developed a serious, extensive and protracted disease, never became immune and usually developed, in addition, a sensitivity to many of the materials used in daily life. Mumford (1934) assumes that the production of some substance derived from damaged skin has lowered its resistance to any irritant; but Hall (1939) concluded that the skin undergoes changes in structure and composition at different periods of life and cites this type of occupational dermatitis and infantile eczema as examples. One such case occurred in a shift worker aged 55 years who was engaged in packing bleach for 41 years (1892-1933). He first noticed a few pimples on the front of the left elbow in March 1933, which quickly spread to other areas. Papules and weeping patches developed on the backs of the hands, forearms and arms, and slight erythema on the neck and inner sides of the thighs. He was obliged to cease work. The condition improved very slowly until 29.6 .34 , when he became free from any eruption, but relapsed after a few days and, in spite of hospital treatment, his skin could not be rendered clear until 2.12.35. Within a few days of his discharge the hands were again affected.

(c) A group of intractable cases occurring in related workers having some features of sensitization dermatitis. Several members of the same family were affected and among the 67 cases already quoted, 8 belonged to this group and there were family relationships thus-two brothers and one nephew; two brothers, father and daughter; while one case had an uncle affected with occupational dermatitis and a brother with psoriasis. The cases as a group are similar and present distinctive features. The initial skin lesions are out of all proportion in extent and severity to the known properties of the causative agent. The reaction is eczematous in type and occurs in areas not exposed to direct irritant action. Relapses are frequent and imply an inherent instability of the skin in which simple external factors (soap, friction, perspiration) induce excessive local response. The history of such cases supports the view that there is little possibility of returning them to regular normal work and if a family history of skin disease is discovered before employment they should be excluded from contact with any known skin irritant.

2. Characteristic eruptions are produced by a number of agents and include chromic acid burns, tar warts and epitheliomata.
Oil rashes are manifested by blackheads and pustular eruptions which occur on parts of the body contaminated by oils, particularly after slight injuries such as those caused by metal filings. This form of dermatitis is produced by blocking and irritation of the skin follicles followed by septic infection by organisms generally derived from the skin surface. Factory Dept. (1932). Whitwell (1943, 1945), however, has shown that all cutting agents are not equally harmful to the skin, and chemical irritation may be the primary cause and not mechanical blocking of the skin follicles.

Acne. The occurrence of acne in industry has been noted for many years and has usually been described under the name of 'chlor acne.' This is a misnomer, inasmuch as exposure to chlorine, or to many compounds containing chlorine, does not give rise to the disease. The majority of workers exposed to the fumes of chlorinated naphthalenes and chlorinated diphenyl will develop acne if the exposure is continued for any length of time. The lesions are seen earliest and most commonly on the face, commencing external to and below the eye to the malar prominence and spreading over the cheeks. Numerous comedones are present behind the ears. Few are present on the forehead and the nose is characteristically spared, as is the mid-line of the face generally. In severe cases the lesions are found on the neck, chest, upper abdomen, arms and extensor aspects of the forearms, particularly about the elbows. The most characteristic feature is the enormous number of very fine blackheads around the eye, and this observation associated with the distribution of the eruption and the absence of noticeable greasiness, distinguishes the eruption from acne vulgaris (Jones, 1941).

\section{B. Secondary Skin Irritants (Sensitization der- matitis)}

Certain types of skin disease are related to hypersensitivity and allergy. Allergy is defined by Bray (1931) as 'exaggerated susceptibility to various foreign substances or physical agents that are harmless to the great majority of persons.' The term should be restricted to designate reactions which occur after a lapse of time following the initial lesion and which are often severe and produced by slight contact with the original irritant. MacKenna (1934), reviewing some of the knowledge concerning anaphylaxis and allergy which has accrued from numerous exact and scientific experiments, stated that an anaphylactic reaction can be obtained in a majority of animals and in man, but a person is not easily made allergic. It seems to be agreed that the percentage of allergic persons in the population is between 0.5 and 1 .

Only a small percentage of cases of occupational dermatitis are inherently allergic in type, but many more occur among the users of finished products. In these cases the patient becomes sensitized to a particular causative factor and will relapse immediately if contact is again established even with minimal exposure. Subsequent attacks are 
likely to be more extensive and intractable. There appears to be a danger that, if a severe attack is experienced the skin may become so affected that contact with any irritant will cause a relapse. Irritants which give rise to sensitivity include many dyes and intermediates, and Ingram (1942) states that the local application of sulphonamides may produce sensitization, while Tate (1944) records epidermal sensitization with eczematous reaction produced by local application of sulphonamides which may be so intense as to preclude their subsequent administration in effective doses for other diseases. Sensitization may follow the use of any of the sulphonamides.

The type of reaction produced is often characterized by the sudden onset of erythema, oedema and weeping dermatitis associated with severe irritation -often widespread and involving the face and other exposed parts. In atopic sensitization reactions occur away from exposed areas.

It has been shown that by cutaneous administration of simple chemical compounds, such as $2: 4$ dinitrochlorbenzene, in small quantities, a typical incitant of contact dermatitis in man, it is possible to induce true anaphylactic sensitization in guineapigs, demonstrable by the intravenous injection of protein conjugates. Landsteiner and Chase (1937) suggest that this is strong evidence in favour of the formation of antigenic conjugates following application of substances of simple chemical constitution. Sensitivity to dinitrochlorbenzene may be extreme and four individuals were found to develop severe reactions from a 1 in $1,000,000$ solution (Jones, 1934). The following history illustrates a case of this type:

H. T. Born 12.8.82, a chemical process labourer, developed erythema and oedema on the forearms, arms, neck and face on 22.1.16 from contact with dinitrochlorbenzene dust. He recovered in 3 weeks but relapsed immediately after contact with the same material and was absent for 6 months during the second attack and has not been free from symptoms since. On 14.12.33 he was tested with dinitrochlorbenzene in alcohol and reacted violently to one drop of 1 in $1,000,000$ solution.

The areas affected on 17.5.34 were the backs of the hands and fingers which were red and cracked and the flexor aspects of the forearms which showed erythema and papules. Repeated attacks of erythema, papules and weeping occur on the hands, face, forearms and thighs without obvious cause.

\section{Diagnosis}

The diagnosis of occupational dermatitis may be difficult as in most cases the changes in the skin are no different from those that occur in dermatitis or eczema of non-contact origin and there is no specific type of reaction corresponding to any particular irritant. The early diagnosis of the condition is of the highest importance to treatment. The removal of the person from contact prevents the development of the intractable type of case which develops sensitivity to a multiplicity of agents. Schwartz (1940) stresses that the two most important factors in the diagnosis of occupational dermatitis are the history and the site of the eruption. However, the diagnosis must mainly depend on a full consideration of the mode of development of the eruption, its distribution in relation to areas exposed to irritation, the exact nature of the work and irritants handled, and the materials used to cleanse the hands, together with the patient's previous skin history (Thomas, 1939). Horner (1934) stresses the frequent fallacious description of the work performed by the patient which is no guide to the actual cause. An attempt should be made to establish the following points in each case:

1. Whether an occupational causal factor has been established at some previous time.

2. Contact with an agent known to produce similar changes in the skin has occurred.

3. The time relationship between exposure to the agent and onset of the dermatitis is correct for the particular agent and abnormality of the skin.

4. The site of onset of the skin disease is the site of maximum exposure.

5. The lesions present are consistent with those known to have followed the reported exposure or trauma.

6. The individual is employed in an occupation in which similar cases have previously occurred.

7. No exposure outside occupation can be implicated.

If dermatitis is established the following confirmation is important:

(1) Evidence of previous attacks after exposure followed by improvement after cessation of exposure. Many cases improve at weekends or after holidays.

(2) Patch tests corroborate the history and clinical findings. (Foerster, et al., 1942, 1943.)

\section{Site of Eruption}

The site of the disease is related to the physical nature of the irritant and also to chemical factors which determine its class, in addition to the mechanical effects of the process being worked. Dermatitis produced by direct contact appears commonly on the backs of the hands and fingers, and flexor aspects of the forearms; while the palms usually escape. Liquids may splash or spray and the face may consequently become affected. Dust spreads widely and causes an eruption on the neck, axillae, perineum, genitals, feet and ankles, and belt area, i.e. the sites of friction. The skin is comparatively thin over the inner surface of the forearm and the upper arm, and these areas are often affected. True industrial dermatitis of the eczematous type always begins on the parts most exposed to the action of the irritant causing it, and in the majority of cases these are the hands and arms. In severe cases and where sensitization occurs the rash may spread to other parts of the cutaneous surface remote and well protected from the direct action of the irritant. The eruption may persist in these parts, as well as on the exposed parts, for an indefinite period with 


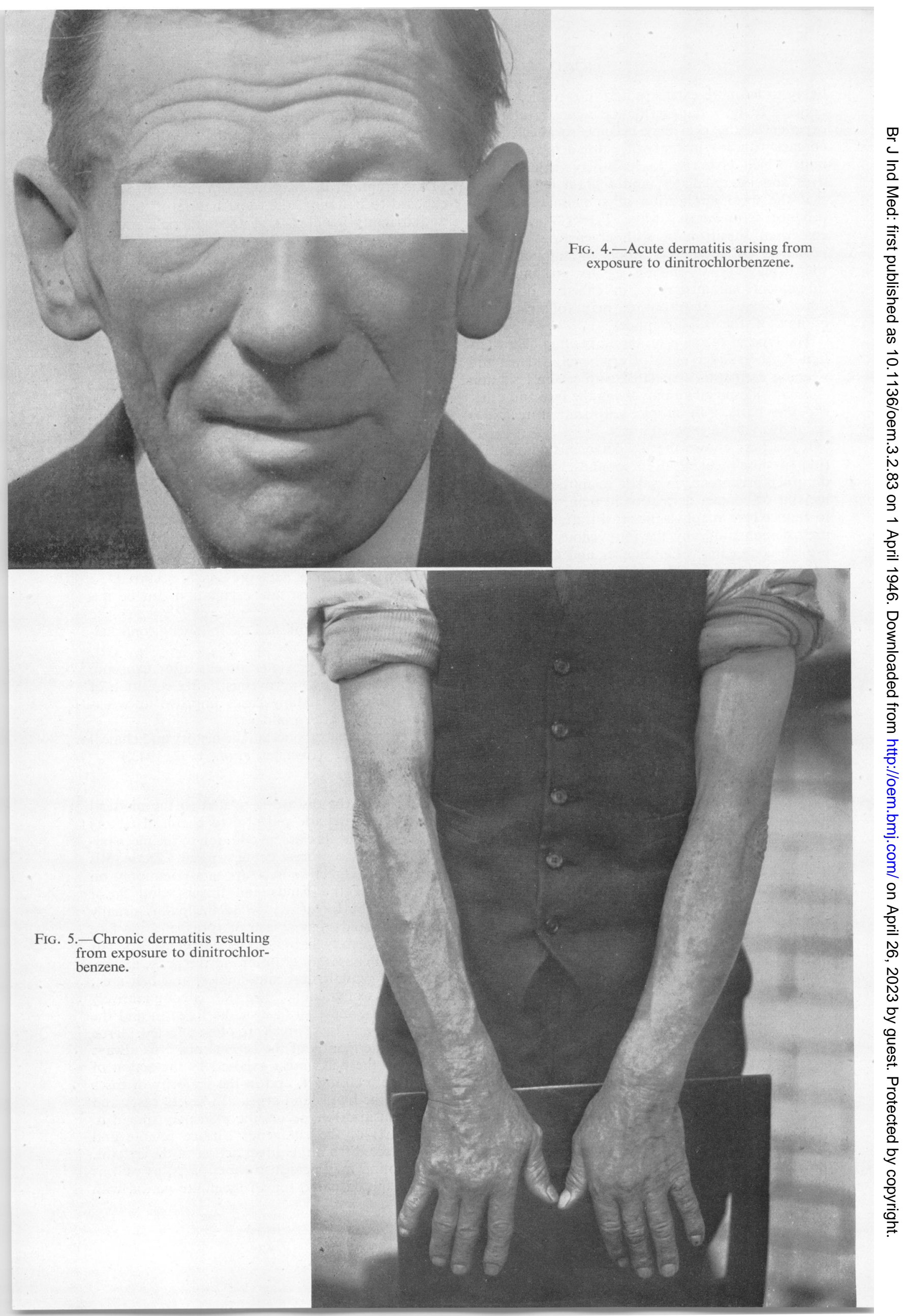


remissions and relapses. In fact, it behaves like a constitutional eczema, from which it can only be distinguished by the history of its original incidence (Haldin-Davis, 1939). Some consider that a dermatitis due to work cannot persist for a long period after the removal of the alleged irritant, but others hold that the human skin which has once been attacked by occupational dermatitis may acquire a habit of breaking down, and becoming sensitive to agents and influences which were previously harmless.

\section{Appearance of Eruption}

The appearance of the lesions is proportional to its stage and severity; and various types have already been considered. In a majority of cases the eruption is not characteristic and difficulty arises in those cases which resemble constitutional eczema and where there is no obvious contact between the skin and an irritant. Stokes (1930) has defined eczema as a dermatitis in which the constitutional outweighs the exciting cause, but the word is used in different senses and by it the majority of English dermatologists mean an inflammation of the skin in which the epidermis is most conspicuously involved showing the histological changes known as spongiosis. Clinically tiny vesicles are formed. It is clear that eczema must have a large variety of causes and it is unsound to call the disease ' eczema' when the noxa is unknown and exclude from this title identical manifestations produced by a known noxa. The connection between eczema and 'dermatitis,' in which participation of the papillary body and cutis is more pronounced, is very close and clinically it makes little difference whether the epidermis or dermis is the seat of primary damage, for it is impossible for a reaction to take place in either without secondarily influencing the other. The difference in the site of maximum reaction may be largely a matter of intensity and exogenous eczema-producing substances, if in too weak concentration or used for too short a time, produce an erythema. The proportion of cases of eczema attributed to external noxae varies with the energy expended in searching for them (Goldsmith, 1936). MacCormac (1937) points out that the age of incidence of idiopathic eczema and industrial dermatitis, particularly in males, have a very similar curve. Probably eczema and dermatitis are one and the same reaction and are the same condition pathologically, but not aetiologically; it is, therefore, essential to distinguish between eruptions caused by exogenous irritants and those produced by internal constitutional causes. Familial diseases such as infantile eczema, asthma, hay fever, urticaria must be recognized and considered in arriving at a diagnosis. Hallam (1938) separates dermatitis into traumatic, atopic (which includes infantile eczema and sequelae) and sensitization (often referred to as eczema). He considers that infantile eczema and prurigo should be regarded as an entity and distinguished from other eczemas. Atopy also includes predisposition to particular types of allergy such as asthma and hay fever.

It is impossible, therefore, to establish a diagnosis of occupational dermatitis from the appearance of the eruption in a high proportion of cases, and the following principles should be fulfilled. The aforementioned criteria should be satisfied; the causative agent should be identified if possible and classified skin diseases must be excluded before the diagnosis is established.

\section{Identification of Irritant}

The isolation of the responsible irritant may be difficult. In spite of the complexities and variations of individual response and the immense number of potential irritants, the clinical picture varies but little. The exact cause cannot be recognized from the symptoms alone; they consist of erythematous, irritable, diffuse patches - of various sizes, round or oval in shape-and moist, dry, fissured, or scaling according to the stage in which the patient presents himself and not infrequently according to what has been applied for relief (Semon, 1939).

Many different substances cause dermatitis and, if suspected, can be applied to the skin in the form of a patch test. An adequate review of this method of diagnosis calling attention to some of the difficulties and necessary precautions is recorded by Levin (1942). A careful technique is necessary. Different parts of the body vary in sensitivity and tests should be applied as near as possible to the site of inflammation. Patch tests are an important aid to diagnosis, but responsible for many errors when relied on for diagnosis, and when used to detect primary irritants. Their value lies in deciding the cause of hypersensitivity dermatitis and mistakes may be avoided by a careful history. Clinical experience suggests that states of hypersensitivity to a chemical irritant which in full strength is a primary irritant will always give a positive reaction to 1 in 10 dilution (Osborne and Hallett, 1942). The conclusion arrived at is that these tests are sometimes of corroborative but rarely of primary diagnostic value in this connection, and, furthermore, that reactions are not specific (Rep. Chief Insp. Fact., 1936). Their practical value is considered doubtful by Silcock (1944).

\section{Differential Diagnosis}

A very large number of skin diseases are outside the influence of occupation and must be excluded. So far as the dermatologist knows, at present, these are produced by internal and quite undetermined causes. Such diseases often mimic or complicate the eruptions due to occupation (White, 1932).

In considering differential diagnosis it is instructive to note the incidence of skin disease in the Out Patients Department of hospitals and skin clinics. There are about 300 skin diseases recorded and one-third of these are fairly common, 20 are common in general practice. Ninety-five per cent. of cases of skin disease seen at Out Patients Depart- 
ments are inflammatory and either due to some external cause, and can be considered as manifestations of occupational dermatitis or eczema, or to septic infection such as impetigo or furunculosis, or to various permutations and combinations of these conditions. The remaining 5 per cent. consist of scabies, alopecia areata, ulcers of the legs, tinea infections and an occasional lichen planus or pityriasis rosea (Haldin-Davis, 1935). Semon (1939) after thirty years' experience in Out Patient Clinics states that the incidence of industrial dermatitis averages about 10 per cent. of all cases treated. Roxburgh (1944) is of the opinion that thirty common skin diseases are mistaken for industrial dermatitis. Among the chief diseases to be considered the following are important:

Scabies.

Lichen planus.

Syphilis.

Varicose dermatitis.

Pompholyx.

Mycotic dermatitis.

Impetigo.

Pityriasis rosea.

Seborrheic dermatitis. Erythema multiforme.

Pediculosis.

Psoriasis.

Urticaria.

Drug eruptions.

Dermatitis herpetiformis.

Ichthyosis.

Flexural eczema. Lupus erythematosus.

Folliculitis (Sycosis). Intertrigo.

Ery. Scarlatiniforme. Prurigo Aestivale.

In differentiating them it is important to examine the patient stripped. Fungus infections of the hands are not very common and the agent should be demonstrated to establish the diagnosis. The feet are commonly affected and can often be diagnosed on clinical grounds. Epidermophytid eruptions on the hands are common and may be mistaken for occupational dermatitis. Pompholyx is an acute bullous dermatitis of hands and less commonly of the feet, sometimes caused by allergy towards epidermophytes or pyogenic cocci or by endocrine, metabolic or sympathetic dysfunction.

Plates 8 and 9 illustrate a case of occupational dermatitis caused by exposure to ammonia and resembling psoriasis.

\section{Legal Aspects}

A diagnosis of 'dermatitis produced by dust or liquids ' can for the purpose of compensation under the Act only be made by a practitioner appointed as examining factory surgeon. The certificate so given holds as a legal document unless challenged by appeal to a medical referee within the statutory period. Industrial disease is for Workmen's Compensation Act purposes regarded as a notional accident, so that subsequent allergy or sensitivity does not affect the issue if the original cause can be associated with occupation (Morgan, 1939).

The wording of the Act is "dermatitis produced by dust or liquids' and it is agreed on the medical and legal sides that eczema and dermatitis are one and the same reaction. The Act, however, covers more than these forms of eczematous dermatitis from direct irritation or from sensitization. All forms of eczematous dermatitis, including con- stitutional and seborrhoeic forms, may be produced or provoked by occupational dust or liquids. Ingram (1939), points out that the legal question is whether a particular workman contracting eczematous dermatitis while working under certain conditions would have suffered from similar trouble had he not been so working. As the law stands at present almost any skin disease may be certified as due to occupation and, although real dermatitis is common enough, certificates have been known to include among other conditions actual cases of eczema, scabies, psoriasis and lichen planus. The medico-legal aspect is difficult and comprehensive reviews with useful practical information are given by Schwartz (1943a), and by Mumford (1934, 1935), who advises that a panel of dermatologists should be available so that a report of a specialized nature on a case under argument could be made. Senior physicians with many years of specialized experience should be appointed to the panel.

In the future there should be closer co-operation between the medical practitioners concerned in the settlement of cases. The Works Medical Officer should have a real knowledge of the actual work performed, the length of exposure and materials used and complete records of previous skin diseases occurring on any process. The Dermatologist can exclude any well-defined constitutional skin condition and in general establish the diagnosis and prescribe treatment. The Family Practitioners should have intimate knowledge of the home circumstances, history of previous skin disease and the development of the eruption. The referee should be an independent dermatologist appointed by the Factory Department.

\section{Prevention}

A great deal can be done to prevent occupational dermatitis by precautionary measures applied to personnel and plant.

1. Supervision of personnel. Selection by pre-employment examinations. Instruction.

Medical supervision and first aid.

2. Direct protection.

Factory hygiene and design of plant.

Protective clothing.

Barrier creams.

\section{Cleansing.}

Provision of adequate washing facilities, with routine supervision:

These measures, which have been reviewed by MacKenna (1936) and Horner (1942), are of the highest importance and require urgent application to industry. A substantial reduction in the total cases of Industrial Dermatitis occurring in the filling factories of the Ministry of Supply was secured by supervision of ablutions, the application of barrier substances, the elimination of susceptible workers, and the development and mechanization of many processes (Rep. Chief Insp. Fact. 1943). Most cases caused by primary irritants can be prevented 


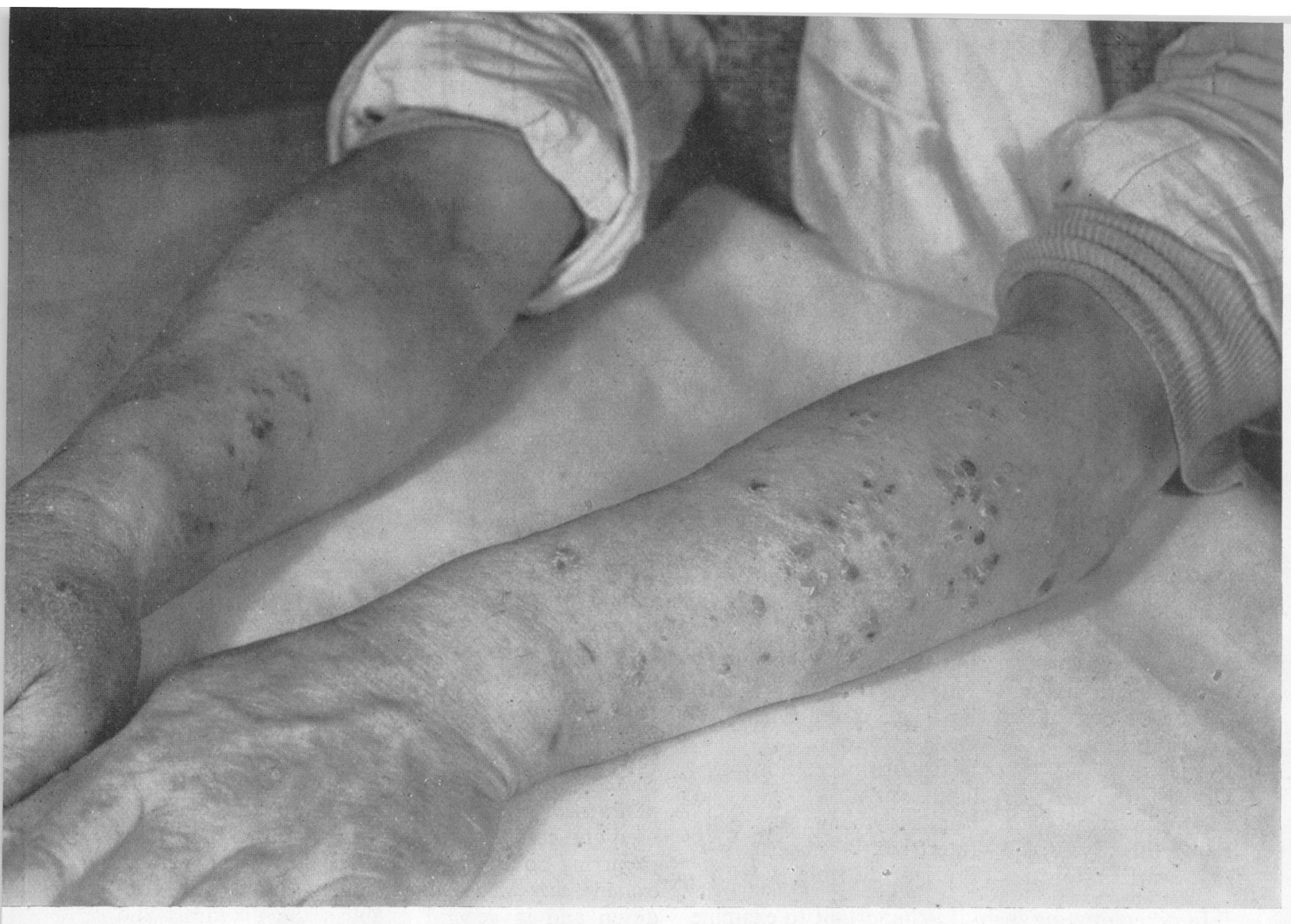

FIGs. 8, 9.-Occupational dermatitis produced by ammonia.

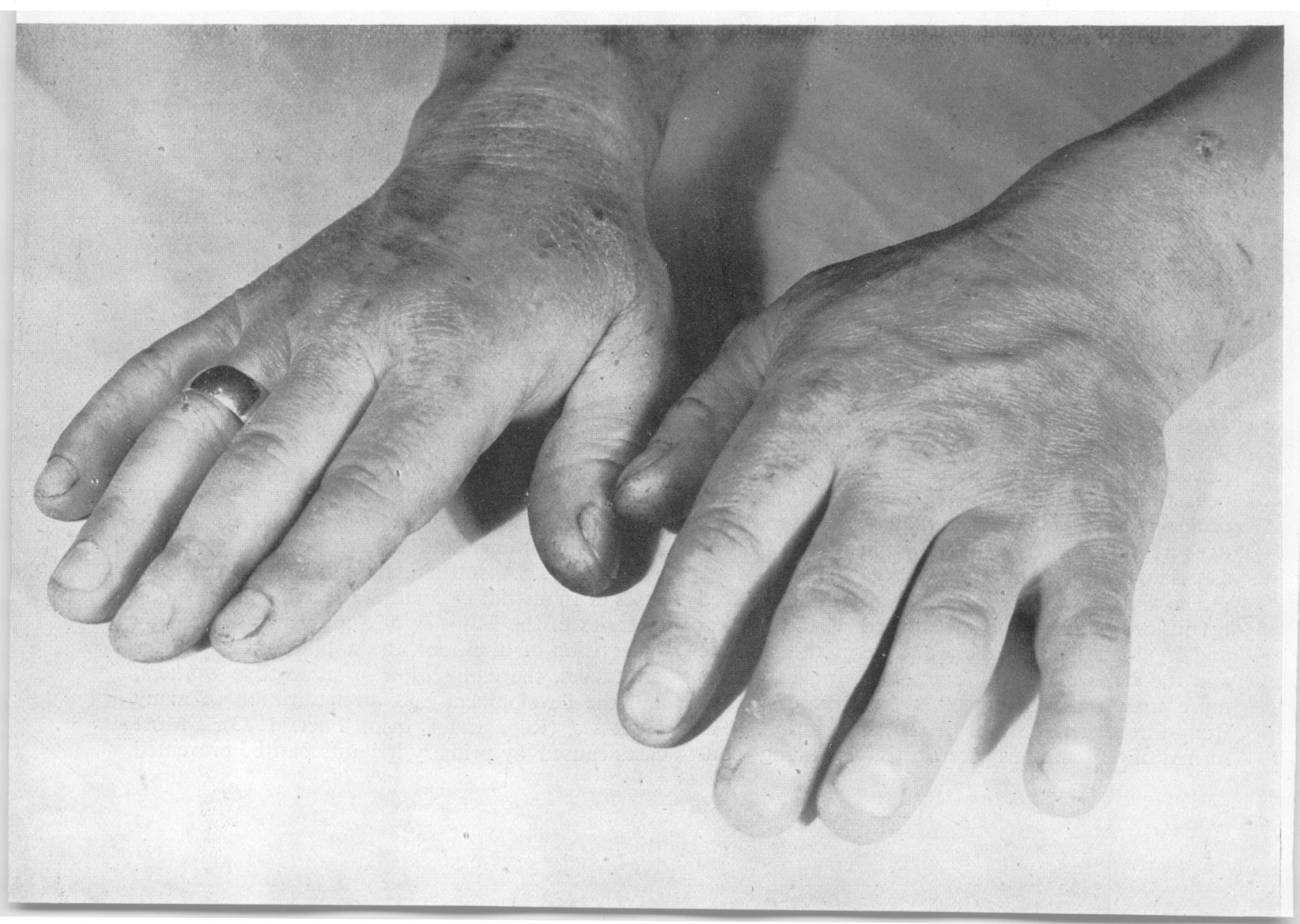

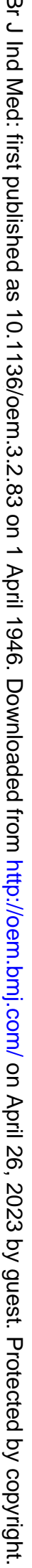


by mechanical protection and proper education of workers. The importance of skin cleansers and the abolition of abrasives and hand brushes is stressed in a review of preventive measures by Reuter (1941). Collier (1935) is convinced that the most important factors in the control of occupational dermatitis are the discovery of the susceptibles, the control of excessive heat, and the reduction of exposure to the specific skin irritant. No single method is effective for the purpose and consideration must be given to all types of protection (Bourne, 1944).

\section{Examination of Prospective Employees}

This should be conducted by the Industrial Medical Officer who is aware of the particular skin hazards. It is desirable to choose workers with a ' good skin' for occupations known to give rise to dermatitis. A good skin is defined as 'one that is of considerable thickness when raised between the finger and thumb, is not too dry, and has no obvious defect such as pimples" (Factory Dept., 1939). People with established skin disease or a recent history of skin disease especially of the eczematous type or other evidence of susceptibility should be excluded from work with potential skin hazards. Dermatitis is likely to recur (Ministry of Labour and National Service, 1943). It is well known that some people are more susceptible to dermatitis than others. Certain irritants will cause dermatitis in any subject, but the majority require an individual susceptibility (Macleod, 1933). Apart from established skin disease susceptibility to occupational dermatitis may be indicated by either a congenital disability such as ichthyosis or by acquired disabilities as a lowered skin resistance from general illness or morbid cutaneous conditions such as seborrhoea and excessive sweating. Itching caused by any skin disease is likely to predispose to occupational dermatitis. It is generally agreed that the seborrhoeic individual is prone to generalized skin affections and is unduly sensitive to irritants. People with varicose veins are prone to develop a generalized skin eruption. General illness may lower the resistance of the skin; Gardner (1922) has even suggested that general illness proceeded dermatitis in 77.4 per cent. of cases, and Mumford (1936) has said that anaemia and dysfunction of the thyroid predispose to skin disturbances. Pyorrhoea and dental sepsis as well as other foci of infection predispose to and later aggravate eczematous eruptions. Pre-employment examination should take special note of these conditions; and obviously any person who has had dermatitis or gives a family history of dermatitis should not be exposed to any fresh hazards. It is a strange fact, however, that in examining the 2000 people for the chemical industry no family history of dermatitis was ever obtained. Patch tests are of little value in selecting people for employment.

\section{Instruction of Personnel.}

A frank statement of the risks involved and the method of contraction of occupational dermatitis should be given to workers in hazardous occupations. They should be instructed in cleanly methods of work; how to control dust and keep their benches clean. Foremen and forewomen should be instructed in the principles of the prevention of occupational dermatitis and in normal skin hygiene. Cautionary notices should be displayed in workrooms and washing rooms (Factory Dept., 1932, 1939).

\section{Inspection of Established Employees}

This is a measure of the highest value. Repeated and frequent examination of the skin of all process workers and casual contacts should be instituted to detect early signs of skin lesions. Immediate removal of such cases from contact may prevent the development of extensive disease which results in general sensitivity of the skin, as apart from individual susceptibility, the chance of recurrence varies directly with the severity and duration of the primary or subsequent attacks of dermatitis.

The early reporting of all lesions should be encouraged and propaganda established to promote application for first aid for all cuts and minor injuries.

\section{Factory Hygiene and Design of Plant}

This is a problem for the engineer in co-operation with the medical officer and is obviously a first principle. Its aim is to prevent actual contact with material irritants by plant design. The importance of this measure is well illustrated by the fact that 45 per cent. of operatives will contract acne if exposed to the fumes of chlorinated naphthalenes (Jones, 1941). In a small chemical factory employing 80 people, 31 contracted occupational skin diseases during a period of one year due to the small scale of the operations where there was a maximum of skin contact with the materials used. Not enough attention is paid to factory hygiene and plant design at the present time. Mechanization and total enclosure of all industrial processes where known skin irritants are present should receive increasing attention. General measures such as ventilation and temperature control are important. Dust should be curtailed by general or local exhaust ventilation, by wetting and vacuum cleaners. Clean benches, adequate working space and the design of tools with adequate handles to reduce contamination of the hands are necessary matters for consideration. The use of dirty rags for wiping the hands should be forbidden.

\section{Bärier Substances}

Barrier substances may be used by themselves or as additional protection with gloves against corrosive substances. They render washing easy so that soap usually suffices for this purpose, but are of doubtful value against continuous and severe exposure and should be designed so as to remain on the skin and provide protection for an adequate period. The problem of the provision of barrier creams is very difficult and they should be selected 
for each individual irritant. Their provision without care may be dangerous and a fatty barrier cream may increase the absorption of substances soluble in fat, such as T.N.T., nitrobenzene.

Certain criteria for barrier substances were advanced by the Ministry of Labour and National Service (1943) and preparations should be nonirritating to the skin, insoluble in the substance against which the skin protection is required, easily applied, not slippery and easily removed. Peters (1942) points out that barrier creams may be made attractive by tinting and should be correctly applied in a thick even layer. Mumford (1939), discussing the value of various preparations, advanced criteria for the ideal protective and suggested the use of Halden's emulsifying bases. He advances the following classification of types of skin protective:

(1) Fats and oils-for example, petroleum jelly, lanolin, wax, etc.

(2) Jellies of colloid structure-for example, starch, tragacanth, agar, glycerine, honey.

(3) Emulsions containing mixtures of substances in Groups (1) and (2).

(4) Soap bases-for example, stearates, oleates, and palmitates of alkalis: free alkali is usually present.

Schwartz (1942) has recently reviewed this problem and described the following six classes of protective applications:

1. A simple vanishing cream which, when rubbed into the skin, fills the pores with soap and facilitates the removal of dirt when washing after work.

$\begin{array}{llllr}\text { Stearic acid .. } & . . & . . & 20 \\ \text { Sodium carbonate } & . & . . & 2 \\ \text { Glycerine } & . & . & . . & 6 \\ \text { Water } & . & . & . & 78\end{array}$

2. Ointments, emulsions or solutions of ' invisible glove' type, water soluble or water insoluble. Fats or oils may be added to prevent the removal of the water soluble type by perspiration. The water insoluble resins or waxes require a volatile solvent for application and a special cleanser for removal. Possible irritant effect may be minimized by the application of hydrous wool fat cream after work.

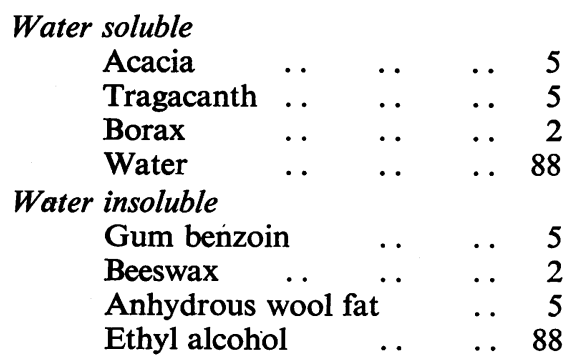

3. Ointments that fill the pores with a harmless fat, and protect against water soluble irritants and petroleum oils and to some extent against greases.

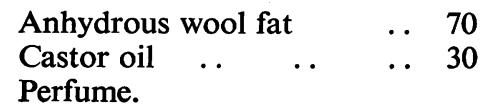

A wetting agent may be added to facilitate removal and to increase penetration of the cream at the time of application because of reduced surface tension.

4. Protective ointments containing non-irritant chemicals to neutralize irritants:

Boric and benzoic acids to neutralize alkalis.

Soap and magnesium hydroxide to neutralize acids.

5. Protective ointments which permit inert powders to adhere to the skin and form a protective covering.

These are useful against abrasives and allergenic substances, e.g. explosives:

$\begin{array}{lcccr}\text { Zinc oxide } & . . & . . & . & 5 \\ \text { Talc . } & . . & . . & . & 5 \\ \text { Iron oxide } & . . & . & . & 1 \\ \text { Irish moss } & . . & . & . & 2 \\ \text { Gum benzoin } & . . & . & 2 \\ \text { Water } & . . & . . & . & 10 \\ \text { Alcohol } & . & . . & . & 15 \\ \text { Vanishing cream } & . . & . . & 60\end{array}$

Talc powder may be used to protect the skin against lime (Pether, 1937).

6. Protective ointment against photo sensitizing agents, such as heavy coal tar.

\begin{tabular}{|c|c|c|}
\hline wool fat & & \\
\hline Cas & & \\
\hline m dioxide & & \\
\hline Methyl salicylate & & \\
\hline $\begin{array}{l}\text { Duponol } \\
\text { Perfume }\end{array}$ & & \\
\hline
\end{tabular}

Most of the proprietary creams are mixtures of the above cleansers.

Klauder, Gross and Brown (1940) describe a number of protective hand creams and detail the formulae of several which are useful for general purposes:

cent.

I. Petrolatum ..

$\begin{array}{lll}\text { Hydrogenated cottonseed oil } & . . & 30.0\end{array}$

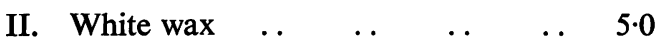

Glyceryl monostearate $\quad . . \quad \ldots \quad 12.5$

Hydrous wool fat $\quad . \quad$. $\quad$. $\quad$. 5.0

Sodium silicate commercial solution $\quad 5.0$

Ammonium hydroxide, 10 per cent. $\begin{array}{llllll}\text { solution } & . . & . & . . & . . & 0.5\end{array}$

$\begin{array}{llllll}\text { Petrolatum } & . & \text {.. } & \text {.. } & \text {.. } & \mathbf{7 2 . 5}\end{array}$

III. To formula II, 5 per cent. by weight of latex is added which produces a rubbery film on the skin.

IV. For prolonged contact with water:

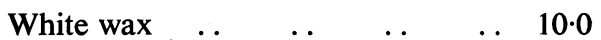

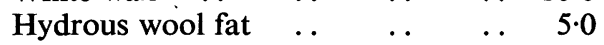

$\begin{array}{llll}\text { Sulphonated olive oil } \quad \ldots & \ldots & 10.0\end{array}$

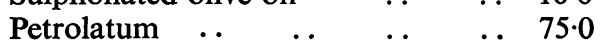


V. Non-greasy preparations which dry on the skin and do not rub off are indicated for dry work and against dust:

Glyceryl monostearate $\quad . . \quad$. 12.0

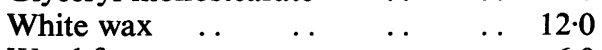

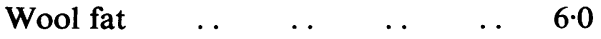

$\begin{array}{llllll}\text { Cholesterol } & \ldots & \ldots & \ldots & \ldots & 1 \cdot 0\end{array}$

Sodium silicate, commercial solution $\quad 5 \cdot 0$

Ammonium hydroxide 10 per cent.

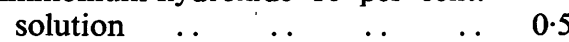

$\begin{array}{llllll}\text { Water } & \ldots & \ldots & \ldots & \ldots & 63.5\end{array}$

\section{Washing Facilities, Cloakrooms and Clothes}

The ideal plan is to provide changing and bathing accommodation at the factory entrance so that workers may enter and immediately change into working clothes. After ceasing work they can bathe and return home in their own clothes. The provision of adequate washing facilities is essential in considering the prevention of occupational dermatitis. Basic information is supplied on the arrangement and equipment of wash-rooms and bathrooms in the Ministry of Labour and National Service Welfare Pamphlet No. 8 (1944). Emphasis is laid upon adequate supervision of the facilities when once provided; this is of importance and often overlooked. Examples of washing facilities in different kinds of factories are given with photographs and information about the provision of soap, towels, nail-brushes and baths. Various types of wash basins and details of drainage are shown. Hot and cold water or mixing valves should be provided. Circular fountains or long porcelain troughs are satisfactory types of wash bowls. A good system is to fit the basins without traps and discharge the waste into a glazed channel which communicates with a trapped gully outside the building. Shallow foot-baths provided with showers in a private cubicle adjoining a dressing-room are excellent examples of bathing accommodation.

\section{Skin Cleansing}

The best routine method of cleansing the skin is by the use of a good toilet soap and plenty of warm water. This is used for general purposes at noon and at the end of the day. Schwartz (1942) has recommended a good soap as a superfatted neutral toilet soap containing a wetting agent or synthetic detergent. There should be a minimum of free alkali and the $p \mathrm{H}$ should be 10 or less in 1 per cent. solution. No silica, quartz, pumice, feldspar, resin fillers or organic solvents should be used. The following formula is given:

$\begin{array}{lllr}\text { Neutral toilet soap } & \ldots & \ldots & 30 \\ \text { Bentonite } \ldots & \ldots & \ldots & 30 \\ \text { Santomerse } \ldots & \ldots & \ldots & 10 \\ \text { Hydrous wool fat } & \ldots & \ldots & 5 \\ \text { Perfume } & \ldots & \ldots & 1\end{array}$

Klauder, Gross and Brown (1940) stress the adverse effects of the use of various cleansing agents in a review of preventive methods. By the adoption of general preventive measures, and barrier creams it is usually possible to facilitate the removal of general dirt and so prohibit the use of abrasives, solvents, soda ash and bleach and acids which often produce dermatitis by themselves. It must be stressed that if efficient substitutes are not provided workers will, of necessity, use these materials which are generally available in chemical works. Even so it may be necessary to develop and provide special cleansing agents for the particular problems. The removal of dyes is often difficult and, for example, solutions of hypochlorite and bisulphite can be provided for the removal of such staining. Nail-brushes are intended for cleaning nails only and much damage can be done by plying these as scrubbing brushes to the skin. Tar, tar rubber, bitumen, oil, paint, turpentine and grease can all be removed by the use of cotton-seed oil, 50-140 c.c. being placed in a bowl and the hands washed therein. The hands are subsequently washed with soap and water.

A useful description of skin cleansers and measures of prevention and treatment of occupational dermatitis is recorded by Schwartz (1941a). The combination of sulphonated castor oil $(p \mathrm{H} \mathrm{7 \cdot 2-}$ oil content 50 per cent.) and a wetting agent such as duponol makes a good skin cleanser and does not defat the skin. The addition of an alkali such as trisodium phosphate 1-2 per cent. increases the cleansing powers and only slightly increases the irritant properties, and a mild perfume such as lavender or lilac makes the mixture more acceptable. The preparation has been used successfully in the same way as liquid soap (Schwartz, 1941b).

The prevention of oil rashes requires special consideration. Ordinary washing with soap and water is not effective in cleansing the skin before and after work and preventing these rashes. The Factory Dept. (1932) recommended that the hands and arms should be washed before work with soap and water and protective clothing carefully adjusted. First aid must be obtained for cuts and sores. After work the hands and forearms should be washed in a lotion having the following composition:

\begin{tabular}{|c|c|c|c|c|}
\hline \multicolumn{3}{|l|}{ Chlorinated } & & 175 grains \\
\hline Bicarbonate & oda & & & 350 \\
\hline Boric acid . . & - & . & & 35 \\
\hline Water & . . & $\cdots$ & & 30 ounces \\
\hline
\end{tabular}

Before use, mix with ten times the quantity of water. After the use of this lotion the skin should be rinsed well with soap and water.

Mummery (1944) stresses the value of neutral sulphonated castor oil in a 2 per cent. wetting agent as a substitute for the use of soap after work in preventing oil acne. Oil should be protected from dust, strained and renewed when contaminated. It can be treated by filtering and heating to $300^{\circ} \mathrm{F}$. Twort (1934) describes the measures which should be taken to prevent mineral oil and tar dermatitis and cancer.

The essentials of satisfactory cloakroom accommodation are detailed and plans illustrating the layout and space required are also shown in the 
Ministry of Labour and National Service Welfare Pamphlet No. 8 (1944). Means for drying wet clothes are necessary. An excellent type of locker is one with a slanting top preventing the accumulation of litter and with screened doors which facilitate inspection. The importance of supervision and the maintenance of scrupulous cleanliness must be stressed. Dirty and excessive clothes are common predisposing causes of dermatitis, so that regular and adequate laundering should be observed.

Gloves, aprons and trousers can be made of closely woven cotton fabrics. Rubber aprons should be worn for very wet work. Sleeves made of closely woven cotton are useful in prophylaxis and treatment.

Gloves cause skin changes of an eczematous nature by maceration of the skin and should be worn as little as possible and as loose as possible. Care should be taken to see that they are clean and dry and regularly inspected. Talc or other suitable dusting powder can be used inside the glove. Leather gloves render the skin susceptible to fungus infections and a powder should be applied to the hands to prevent this. The following formula is advised by Ferguson (1944):

\begin{tabular}{llllr} 
& & & \multicolumn{2}{c}{ gm. } \\
Salicylic acid & $\ldots$ & $\ldots$ & $\ldots$ & 5 \\
Menthol & $\ldots$ & $\ldots$ & $\ldots$ & 2 \\
Camphor & $\ldots$ & $\ldots$ & $\ldots$ & 8 \\
Boric acid & $\ldots$ & $\ldots$ & $\ldots$ & 50 \\
Starch .. & $\ldots$ & $\ldots$ & $\ldots$ & 35
\end{tabular}

\section{Treatment of the Skin after Work}

If special agents are used to remove material from the skin, especially if they cause defatting, it is essential to provide a substance to maintain the skin in good condition. For this purpose equal parts of lanolin and olive oil or cotton-seed oil can be used. The application of lanolin to the hands at night is probably one of the simplest and most satisfactory prophylactic measures yet evolved (MacKenna, 1936).

\section{Treatment}

It is essential to establish an early correct diagnosis in order that the patient may be removed from contact with the causative irritant. For this purpose a scheme of alternative work should be organized, and it is of benefit in mild cases if the employee can remain at work without reduction of wages. Experience indicates that it is wise to seek the opinion of a dermatologist at an early stage in severe or doubtful cases. The benefits of rest and hospitalization for severe cases, acute or chronic, are striking, and prolonged convalescence will help in preventing recurrence of the disease. MacKenna (1945) has indicated that rehabilitation can be applied to cutaneous diseases.

At the earliest signs of a skin eruption the patient's skin should be adequately cleansed and all his clothes changed. The irritation produced by the eruption causes scratching which leads to aggrava- tion, secondary infection and loss of rest. The advantages of treatment by sedatives such as bromides and luminal are well known, and phenacetin and phenazone are useful. If the disease is very acute a single dose of 15 grains of chloral hydrate may be effective. It is doubtful if thiosulphates are effective as non-specific desensitizers. Generally adequate meals with additional vitamin $\mathrm{C}$ are required and special diets appear to have little practical value unless the dermatitis is associated with some general disease such as diabetes or nephritis. Hellier (1938) and Wallace (1938) discussed the value of diet and internal treatment in skin diseases. They state that in eczema there is possibly a tendency to acidosis. Excess sodium chloride favours eczema, the sodium ion being particularly important, while calcium, magnesium. and possibly potassium have the opposite effect. The disease is accompanied by a retention of fluid in the skin and this is promoted by carbohydrates and fats and opposed by proteins, and is also affected by the total intake of the patient. The administration of alkalis and the avoidance of sodium chloride are recommended and the following mixture advised:

Calcium lactate.

Magnesium chloride.

Potassium chloride aa $10 \mathrm{gr}$.

Aqua Chlorof. ad $\frac{1}{2}$ oz. t.d.s. p.c.

In eczematous types of lesions the fluid intake and carbohydrate may be restricted. Tea can be taken without sugar, and potatoes, sweets, pastries and bread can be reduced. Plenty of lean meat and milk are advised.

\section{Local Treatment}

Certain principles of treatment were reviewed in an excellent article by Haldin-Davis (1935). Many remedies increase such inflammation as is already present. Antiseptics if employed should be highly diluted. The more acute the inflammation the milder the remedy to be used. Protection of the inflamed surface is the first principle. Gentle wiping with cotton wool soaked in liquid paraffin or olive oil should be employed for cleansing purposes as the inflamed skin reacts badly to water. Sulphonated oils are important cleansing agents for workers who have developed dermatitis and the following formula can be employed:

\begin{tabular}{lllc} 
& & \multicolumn{3}{c}{ Per cent. } \\
Sulphonated olive oil & $\ldots$ & $\ldots$ & $50-60$ \\
Light liquid petrolatum & $\ldots$ & $\ldots$ & $40-50$ \\
Gelatin, 25 per cent. aqueous solution & 10
\end{tabular}

In treating septic diseases of the skin it is most important to cleanse the surface from accumulated discharge without wounding the tender epidermis. If the eruption is wet, calamine lotion or boric acid solution may be used; but if the eruption is dry it is better to employ zinc oxide or boric acid ointments. Ung. zinc oxide (B.P.) consists of zinc oxide 
with soft paraffin and 15 per cent. of lanolin and is very suitable for all forms of dermatitis. It may be used as follows:

Ung Zinci (B.P.).

Paraff. molle aa 4 drachms.

Lassar's paste is a well-tried and often efficacious preparation. The salicylic acid may be omitted in acute cases and the paste can be softened by the addition of olive oil. Calamine lotion is a popular remedy and may be used for local eruptions or widely employed on gauze. The sulphonamides are effective in certain diseases of the skin, but it is questionable if their use as local applications in superficial infective dermatoses possesses any advantage over rational treatment with older and safer remedies (Barber, 1944). Taylor and Hughes (1944) described the treatment of infective dermatoses with penicillin applied locally in adequate dosage. It is effective in certain skin diseases caused by cocci. Starch poultices are effective in the treatment of acutely inflamed and crusted areas. In cases where old patches are present 1-2 per cent. of liquor picis carbonis in the ointment may produce improvement. Occasional painting with 1-3 per cent. silver nitrate in water will cure troublesome fissures and cracks.

$\mathrm{X}$-ray therapy is a most valuable agent especially in the treatment of chronic dermatitis. The dosage in acute cases is usually $50 \mathrm{r}$., repeated every second day and for less acute disease 60-80 r. twice a week. A total of $400 \mathrm{r}$. should not be exceeded during any period of one month followed by a rest of at least four weeks.

\section{Summary}

A review is given of 92 cases of occupational dermatitis occurring in a period of 10 years in a chemical works employing 2000 people.

Sixty-seven cases were produced by primary skin irritants and 25 by secondary skin irritants.

The diagnosis of occupational dermatitis may be difficult and depends on a full consideration of the mode of development of the eruption, its distribution in relation to areas exposed to irritation, the exact nature of the work and irritants handled, and the materials used to cleanse the hands, together with the patient's previous skin history. It is impossible to establish a diagnosis from the appearance of the eruption in a high proportion of cases. Certain criteria should be satisfied; the causative agent identified if possible and classified skin diseases must be excluded. Patch tests are of corroborative but rarely of primary diagnostic value. A list is given of the chief skin diseases to be considered in differential diagnosis. An account is given of the legal situation and suggestions made for closer co-operation between the medical practitioners concerned in the settlement of cases. Methods of preventing the disease are discussed. No single method is effective, and consideration must be given to all types of protection. Examination of prospective employees, instruction and inspection of employees, attention to factory hygiene and design of plant and the provision of barrier substances are important measures. Adequate washing facilities, cloakrooms and clothes should be provided. Adverse effects frequently result from the use of improper cleansing agents and consideration is given to the provision of efficient materials.

The principles of treatment are reviewed and the value of the opinion of an experienced dermatologist is stressed. The benefits of rest and hospitalization for severe cases are striking.

The literature is reviewed.

\section{REFERENCES}

Barber, H. W. (1944). Practitioner, 152, 290.

Bourne, L. B. (1944). Brit. Med. J., 2, 512.

Bray, G. W. (1931). Recent Advances in Allergy, Churchill, London. Collier, H. E. (1935). Chemical Trade J. and Chemical Engineer, 97, 237.

Factory Dept., 1932 ). Prevention of Oil Rashes. Form 296. H.M.S.O. Cautionary Notice. Form 397, H.M.S.O.

1939). Prevention of Dermatitis. Form 1863, H.M.S.O. Cautionary Notice, Form 367, H.M.S.O.

Ferguson, J. (1944). Textbook of Medical Treatment, 3rd Ed., Livingstone, Edinburgh.

Foerster, et al. (1942). J. Amer. Med. Ass., 118, 613.

(1943). Ibid., 122, 370 .

Gardner, F. (1922). Brit. J. Derm. Syph., 10, 298.

Goldsmith, W. N. (1936). Recent Advances in Dermatology, 1st Ed., p. 222, Churchill, London.

Graham-Little, E. (1935). Brit. Med. J., 2, 107.

Haldin-Davis, H. (1935), Ibid., 1, 289.

Hall, A. J. (1939). Ibid., $2,783$.

Hall, A. J. (1939). Ibid., 2, 783.

Hallam, R. (1938). Lancet, 1, 1259.
Hellier, F. F. (1938). Ibid., 1, 1037.

Hollier, F. F. (1938). Ibid., 1, 1037.

Horner, Sibyl (1934). Ibid., 2, 233.

Ingram, J. T. (1942). Brit. J. Derm. Syph., 54, 22.

Jones, A. T. (1934). M.D. Thesis, University of Liverpool.

Jones, A. T. (1931). J. Industr. Hyg., 23, 290.

Klauder, J. V. Gross, E. F., and Brown, H. (1940). Arch. Derm. Syph., $41,331$.

Landsteiner, K., and Chase, M. W. (1937). J. Exp. Med., 66, 337

Landsteiner, K., and Chase, M. W. (1937). J. Exp. Med.,

Levin, O. L. (1942). Industr. Med. (Editorial),

McCormac, H. (1937). Brit. J. Derm., 49, 409. 103

MacKenna, R. M. B. (1934), Liv. Me

- (1936). Brit. Med. 1 . 605 .

Macleod, J. M. H. (1933). Diseases of the Skin, Lewis, London.

Ministry of Labour and National Service (1943). Memorandum on the Prevention of Industrial Dermatitis, Form 330, H.M.S.O., the Preventic
London.

(1944). Welfare Pamphlet, No. 8, H.M.S.O., London.

Morgan, H. B. (1939). Brit. Med. J., 2, 623.

Mumford P. B. (1934) Ibid., 1, 860.

(1933). Ibid., 2, 874

- (1936). Practitioner, 137, 343.

(1939). Brit. Med. J., 1, 266.

Mummery, H. N. (1944). Ibid., 1, 660.

O'Donovan, W. J. (1932). Ibid., 2, $292 . \quad$ New York State J., 42, 1529.

Osborne, E. D., and Hallett, J. J. (1942). New York

Report Chief Inspector of Factories (1936) (1941). Home Office.

Report 1941) (1943). Min. Lab. and Nat. Service.

Reuter, M. J. (1941). Industr. Med., 10, 147.

Roxburgh, A. C. (1944). Brit. Med. J., $2,672$.

Schwartz, L. (1940). Digest of Treatment, 4, 360.

(1941b). Industr. Mub. Health Rep., 56, 1788.

(1942). M. Clin. North Amer., 26,

1943b). Principles and Practice of Industrial Med., Ed. by

Wampler, First Ed., Williams and Wilkins, Baltimore.

Semon, H. C. (1939). Brit. Med. J., 2, 422.

Stokes, J. H. (1930). Amer. J. Med. Sci., 179, 69.

Tate, B. C. (1944). Lancet, 1, 39.

Taylor, P. H., and Hughes, K. E. A. (1944). Ibid., 2, 780.

Thomas, P. E. W. (1939). Brit. Med. J., 2, 421.

Twort, C. C.. and Twort, J. M. (1934). Lancet, 1, 286

Wallace, H. S. (1938). Brit. Med.J., 1, 1226.

White, R. P. (1928). The Dermatergoses, Third Ed., p. 9. Lewis, London.
(1932). J. State Med., 40, 559.

Whitwell, G. P. B. (1943). Lancet, 2, 394.

- (1945). Ibid., 1, 529. 